\title{
Long-term response rates to infliximab therapy for Crohn's disease in an outpatient cohort
}

\author{
Christopher W Teshima MD, Adrienne Thompson BSc, LeRose Dhanoa BSc, \\ Levinus A Dieleman MD, Richard N Fedorak MD
}

CW Teshima, A Thompson, L Dhanoa, LA Dieleman, RN Fedorak. Long-term response rates to infliximab therapy for Crohn's disease in an outpatient cohort. Can J Gastroenterol 2009;23(5):348352.

BACKGROUND: Infliximab's efficacy in the induction and maintenance of remission in luminal Crohn's disease has been confirmed by randomized, controlled trials. Less clearly described are long-term outcomes in the clinical practice setting since the establishment of regularly scheduled, every eight-week maintenance infliximab infusions. Existing reports describing clinical practice outcomes are limited by short durations of follow-up or by the use of episodic dosing, or focus on safety data rather than clinical outcomes.

OBJECTIVE: To examine induction and maintenance responses to infliximab in an outpatient inflammatory bowel disease clinic.

METHODS: A retrospective chart review was performed. Clinical outcomes were infliximab induction and maintenance responses, defined as the ability to stop and remain off corticosteroids while not requiring additional therapy for active disease.

RESULTS: One hundred thirty-three patients were identified with records sufficiently detailed to be analyzed. Of these, 117 patients (88\%) demonstrated a clinical response to induction; 104 of 117 (89\%) were on concomitant immunosuppressive therapy; 80 of 104 on azathioprine/6-mercaptopurine (77\%); and 24 of 104 on methotrexate (23\%). The mean duration of clinical response was 94 weeks $(95 \% \mathrm{CI}$ 78.8 to 109.2). The proportion of patients who maintained response at 30 weeks was $83.2 \%$, at 54 weeks was $63.6 \%$ and at 108 weeks was $44.9 \%$. Adverse events occurred for 15 of 117 patients (12.8\%), consisting of nine infusion reactions, four serum sickness-like reactions, one rash and one infection.

CONCLUSION: Patients treated with infliximab therapy for luminal Crohn's disease in our outpatient clinic achieved excellent induction and maintenance of response rates, confirming the real-life efficacy of maintenance infliximab established in clinical trials.

Key Words: Clinical practice; Crohn's disease; Immunosuppression; Infliximab

Since the first clinical trials of infliximab were published a $\checkmark$ decade ago $(1,2)$, this antitumour necrosis factor antibody has been widely adopted for the treatment of Crohn's disease refractory to conventional therapy with corticosteroids and/or immunosuppressive therapy with azathioprine, 6-mercaptopurine (6MP) or methotrexate. More recently, the early introduction of combined immunosuppression with both infliximab and azathioprine has been advocated as part of a 'top-down' approach, achieving greater initial control of disease and superior long-term mucosal healing (3). While the efficacy of infliximab for maintenance therapy has been well established
Les taux de réponse à long terme à l'infliximab au sein d'une cohorte de patients ambulatoires atteints de la maladie de Crohn

HISTORIQUE : L'efficacité de l'infliximab à induire et à maintenir la rémission en cas de maladie de Crohn de la lumière intestinale est confirmée par des essais aléatoires et contrôlés. Les issues à long terme en milieu clinique, depuis l'adoption d'infusions d'infliximab d'entretien prévues régulièrement toutes les huit semaines, sont décrites moins clairement. Les rapports existants décrivant les issues en milieu clinique sont limités par la courte durée du suivi, par le recours à des doses épisodiques ou par un intérêt pour les données d'innocuité plutôt que pour les issues cliniques.

OBJECTIF : Examiner la réponse à l'induction et au maintien de l'infliximab au sein d'une clinique ambulatoire de maladies inflammatoires de l'intestin.

MÉTHODOLOGIE : Les auteurs ont effectué une analyse rétrospective des dossiers. Les issues cliniques étaient l'induction de l'infliximab et les réponses au maintien, définies comme la capacité de mettre un terme aux corticoïdes et de ne pas les réinstituer sans nécessité de thérapie supplémentaire contre la maladie active.

RÉSULTATS : Les auteurs ont repéré 133 patients aux dossiers assez étoffés pour être analysés. De ce nombre, 117 (88\%) ont démontré une réponse clinique à l'induction, et 104 des 117 (89\%) prenaient également des immunosuppresseurs, soit 80 sur les 104, de l'azathioprine/6mercaptopurine $(77 \%)$ et 24 sur les 104, du méthotrexate (23\%). En moyenne, leur réponse clinique durait 94 semaines (95 \% IC 78,8 à 109,2). La proportion de patients qui continuaient de répondre lors de la $30^{\mathrm{e}}$ semaine était de $83,2 \%$, de la $54^{\mathrm{e}}$ semaine, de $63,6 \%$ et de la $108^{\mathrm{e}}$ semaine, de 44,9\%. Quinze des 117 patients (12,8 \%) ont subi des effets indésirables, soit neuf réactions à l'infusion, quatre réactions semblables à une maladie sérique, une éruption et une infection.

CONCLUSION : Les patients traités à l'infliximab pour soigner une maladie de Crohn de la lumière intestinale de la clinique ambulatoire ont obtenu une excellente induction et un excellent maintien du taux de réponse, confirmant l'efficacité réelle de l'infliximab d'entretien établie dans le cadre d'essais cliniques.

$(4,5)$, the long-term durability of this response outside of clinical trials has been less well described. In the A Crohn's Disease Clinical Trial Evaluating Infliximab in a New Long-Term Treatment Regimen (ACCENT I), response and remission rates of $43 \%$ and $24 \%$, respectively, were achieved at 54 weeks, but outcomes beyond one year of follow-up were not reported (4). Reports describing infliximab outcomes in clinical practice settings have been published (6-9); however, these are limited by short durations of follow-up (less than one year) or the use of episodic rather than regularly scheduled maintenance dosing. A more recently published Austrian study (10) examined

Division of Gastroenterology, University of Alberta, Edmonton, Alberta

Correspondence: Dr Richard N Fedorak, Division of Gastroenterology, University of Alberta, Zeidler Ledcor Centre, 130 University Campus,

Edmonton, Alberta T6G 2X8. Telephone 780-492-6941, fax 780-492-8121, e-mail richard.fedorak@ualberta.ca

Received for publication November 17, 2008. Accepted December 30, 2008 
TABLE 1

Patient demographics

\begin{tabular}{|c|c|c|c|}
\hline \multirow[b]{2}{*}{ Demographic } & \multirow[b]{2}{*}{ Total } & \multicolumn{2}{|c|}{ Concomitant immunosuppressive therapy } \\
\hline & & Yes & No \\
\hline Patients, n & 117 & 104 & 13 \\
\hline Women, n (\%) & $62(53)$ & $52(50)$ & $10(77)$ \\
\hline Caucasian, n (\%) & $115(98.3)$ & $102(98.1)$ & $13(100)$ \\
\hline Mean age at first infliximab infusion, years $(95 \% \mathrm{Cl})$ & $36.5(34.3-38.7)$ & $36.1(33.8-38.3)$ & $40.0(32.8-47.4)$ \\
\hline Mean time from Crohn's disease diagnosis to first infliximab infusion, years $(95 \% \mathrm{Cl})$ & $11.5(9.9-13.0)$ & $11.4(9.8-13.1)$ & $12.2(8.0-16.4)$ \\
\hline \multicolumn{4}{|l|}{ Anatomical distribution, n (\%) } \\
\hline lleal & $42(35.9)$ & $37(35.6)$ & $5(38)$ \\
\hline Ileocolonic & $37(31.6)$ & $31(29.8)$ & $6(46)$ \\
\hline Colonic & $38(32.5)$ & $36(34.6)$ & $2(15)$ \\
\hline C-reactive protein, mg/L (mean [95\% Cl]) & $16.6(12-21.2)$ & $16.6(11.6-21.6)$ & $16.4(1.3-31.5)$ \\
\hline Concomitant immunosuppressive prescriptions, n (\%) & $104(89)$ & $104(100)$ & $0(0)$ \\
\hline Azathioprine/6-mercaptopurine, n (\%) & $80(68.4)$ & $80(77)$ & - \\
\hline Methotrexate, n (\%) & $24(20.5)$ & $24(23)$ & - \\
\hline
\end{tabular}

long-term responses with infliximab treatment, but again was hindered by episodic dosing. Because the superiority of regularly scheduled (every eight weeks) maintenance therapy has been clearly established $(11,12)$, these reports do not adequately describe the 'real-life' durability of infliximab maintenance treatment. Furthermore, studies $(13-15)$ that have examined the clinical use of infliximab with long-term follow-up and scheduled maintenance dosing have focused on adverse events and safety profiles rather than on clinical efficacy.

Examining the efficacy of infliximab therapy outside of the randomized-controlled trial provides a more effective perspective of expected outcomes in clinical practice and the factors that may affect therapeutic response. The objective of the present cohort study was, therefore, to examine the induction and long-term maintenance responses to infliximab treatment in an outpatient inflammatory bowel disease setting.

\section{METHODS}

A retrospective chart review of all patients with luminal Crohn's disease treated at the Zeidler Gastrointestinal Health Centre, University of Alberta Hospital, Edmonton, Alberta, between July 2001 and July 2007 was conducted. All patients treated with infliximab for both induction and maintenance therapy were identified, and their records were reviewed for demographic information and clinical outcomes.

In all cases, the use of infliximab followed the Canadian Association of Gastroenterology guidelines for infliximab treatment of Crohn's disease (16). Patients whose Crohn's disease responded to induction treatment with infliximab (loading doses at zero, two and six weeks) and who subsequently began maintenance therapy were included in the analysis. Clinical response to induction was defined according to the physician's global assessment 10 to 12 weeks after the first infliximab infusion. The global assessment of response was determined by the physician's documentation of significant and clinically relevant improvement in diarrhea, abdominal pain, extraintestinal symptoms and general well-being. The physician's global assessment has been shown to correlate closely with the Crohn's Disease Activity Index (CDAI), during the initial development and subsequent validation of the CDAI $(17,18)$, and more recently from a Canadian registry (RemiTrac CD, Schering-Plough, Canada) of Crohn's disease patients receiving infliximab (19).

As per protocol, patients receiving the induction dose of infliximab initiated a standard steroids taper regimen - tapering by $5 \mathrm{mg}$ each week to $20 \mathrm{mg}$, then by $2.5 \mathrm{mg}$ each week to $0 \mathrm{mg}$. Maintenance clinical response was defined by the same parameters and by the patient remaining off corticosteroids, and not initiating new therapy for active Crohn's disease. Loss of response was defined as an increase in Crohn's disease-related symptoms accompanied by documented initiation of a corticosteroid; Crohn's disease-related surgery for disease activity; termination of infliximab treatment due to loss of effect; termination of infliximab due to adverse event(s); or termination of infliximab for any other reason. The results were not confounded by the possibility of increased infliximab doses or shorter dosing intervals because this was not an available therapeutic option covered by insurance in our medical jurisdiction at the time. The primary end point was defined as the duration of clinical response to maintenance infliximab treatment. Secondary outcomes included the proportion of patients with an ongoing maintenance response at weeks 30, 54 and 108.

Statistical analysis was performed using the statistical software programs SigmaStat 3.1 and SigmaPlot 10 (Systat Software, USA). Parametric and nonparametric statistical tests were performed, as appropriate. Primary outcome analysis used measures of central tendency and measures of variability. In the secondary analysis, the mean values of continuous variables were compared using the Student's $t$ test, while the Fisher's exact test was used for discontinuous data. $\mathrm{P}<0.05$ was considered to be statistically significant.

\section{Patient demographics}

\section{RESULTS}

The demographic characteristics of the patient population are summarized in Table 1. Fifty-three per cent of the study cohort were women and $98.3 \%$ of the study population was Caucasian. The mean age at initiation of infliximab therapy was 36.5 years 


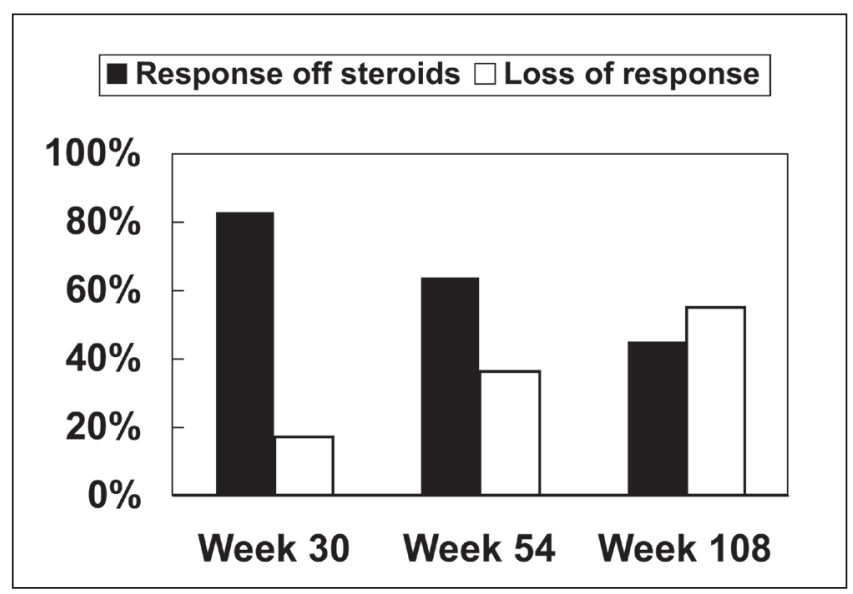

Figure 1) Proportion of patients with infliximab maintenance response and those off corticosteroids. Maintenance of clinical response to infliximab was defined according to the physician's global assessment and the patient being off corticosteroids (solid bar). Loss of response was defined as an increase in Crohn's disease-related symptoms with documented initiation of corticosteroids; Crohn's disease-related surgery for disease activity; termination of infliximab prescription due to loss of effect; termination of infliximab due to adverse event(s); or termination of infliximab for any other reason (open bar)

(95\% CI 34.3 to 38.7 ), and the mean duration of disease (from diagnosis to first infliximab infusion) was 11.5 years $(95 \% \mathrm{CI}$ 9.9 to 13.0$)$. The mean value of C-reactive protein at induction was $16.6 \mathrm{mg} / \mathrm{L}$ (95\% CI 12.0 to 21.2 ). Anatomical distribution of Crohn's disease in the study cohort was 35.9\% ileal, $32.5 \%$ colonic and $31.6 \%$ ileocolonic. Eighty-nine per cent of patients (104 of 117) were on concomitant immunosuppressive therapy, azathioprine/6-MP (80 of 104 [77\%]) and methotrexate (24 of 104 [23\%]). Twenty-six per cent of patients (30 of 117) were using oral corticosteroids at the time of infliximab induction.

\section{Infliximab induction of response}

One hundred fifty-one patients who received a three-dose induction regimen of infliximab were initially identified, of whom 133 had sufficient clinical records to be entered into the study. Of these 133 patients, 117 (88\%) had a clinical response (as defined above) to induction with infliximab and continued with maintenance infliximab therapy.

\section{Infliximab maintenance of response}

The mean duration of clinical response to maintenance infliximab treatment was 94 weeks (95\% CI 78.8 to 109.2). The proportion of patients with ongoing maintenance response (as defined above) at predefined time points was $83 \%$ (94 of 113) at 30 weeks, $64 \%$ (63 of 99) at 54 weeks and $45 \%$ (40 of 89 ) at 108 weeks (Figure 1).

Sixty-one of 117 patients (52.1\%) experienced a loss of response (according to a priori definitions, see Methods section) to maintenance infliximab therapy during the study period. The defined loss of response was due to a loss of clinical effect in 36 of 61 patients $(59.0 \%)$, loss of insurance coverage in 18 of 61 patients $(29.5 \%)$ and adverse events in seven of 61 patients $(11.5 \%$ ) (one osteomyelitis of the jaw, four
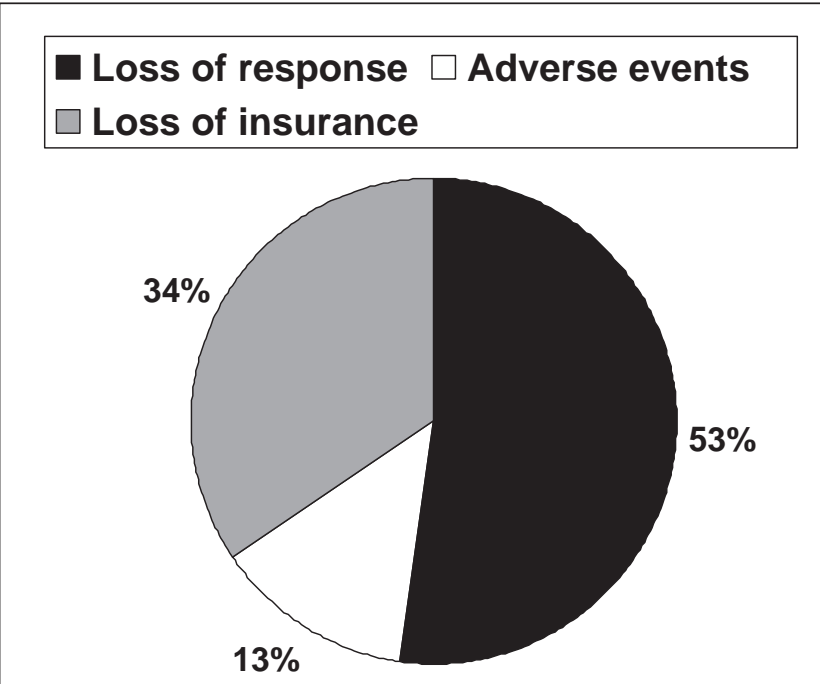

Figure 2) Reasons for stopping infliximab maintenance therapy. Loss of response was defined as an increase in Crohn's disease-related symptoms with documented initiation of corticosteroids; Crohn's disease-related surgery for disease activity; termination of infliximab treatment due to loss of effect; termination of infliximab due to adverse event (s); or termination of infliximab for any other reason (solid pie). Adverse events were identified based on the physician's global assessment (open pie). Loss of insurance represented loss of third-party payer for infliximab (grey pie)

infusion reactions and two serum sickness-like reactions). Of the 36 patients who lost clinical effect to infliximab, corticosteroids were initiated in 10 (27.8\%), Crohn's disease-related surgery for disease activity was necessary in seven (19.4\%) and enrollment into a clinical trial of other investigational treatments in 19 (52.8\%). Interestingly, however, only 52 of 117 patients (44.4\%) actually stopped maintenance infliximab therapy during the study, and nine patients continued treatment despite intervening surgery or corticosteroids, which defined a loss of response. The reasons for stopping infliximab therapy are summarized in Figure 2.

\section{Concomitant immunosuppressive therapy}

The vast majority of patients (104 of 117 [89\%]) were treated with a concomitant immunosuppressive drug for the duration of their infliximab therapy, with 80 of 104 (77\%) on azathioprine/6-MP and 24 of 104 (23\%) on methotrexate. When infliximab-treated patients were stratified according to those receiving concomitant immunosuppressives (azathioprine, 6-MP or methotrexate) and those not receiving this additional treatment, the mean durations of clinical response were 97 weeks (95\% CI 80.8 to 113.2 ) versus 68.5 weeks (95\% CI 25.9 to 109.1), respectively $(\mathrm{P}=0.25)$ (Figure 3$)$. Similarly, the percentage of infliximab-treated patients with clinical loss of response was lower for those on concomitant immunosuppressive therapy (29.8\% [31 of 104]) than for those not on concomitant immunosuppressive therapy (38.5\% [five of 13]), although the difference did not reach statistical significance $(\mathrm{P}=0.36)$.

Of the 30 patients taking corticosteroids at the time of infliximab induction, $73.3 \%$ (22 of 30 ) were successfully weaned, 
with a mean wean time (to a zero dose) of 18.4 weeks (95\% CI 13.2 to 23.6 ). The mean time to wean off corticosteroids was shorter among patients who had a persistent infliximab response than for those who later lost response: 14 weeks $(95 \%$ CI 4.6 to 23.3) versus 22.1 weeks (95\% CI 14.4 to 29.8; $\mathrm{P}=0.20)$.

\section{Adverse events}

In total, including those who stopped and those who did not stop infliximab, 15 of 117 patients (12.8\%) experienced an adverse event while on maintenance therapy. One patient developed osteomyelitis of the jaw, nine patients had infusion reactions, four patients had serum sickness-like reactions and one patient had a nonspecified rash of unclear etiology. There were no cases of tuberculosis, malignancy or death.

\section{DISCUSSION}

The results of the present study demonstrate that the clinical use of infliximab for Crohn's disease treatment broadly reproduces the efficacy achieved during the randomized controlled trials. The $88 \%$ induction response rate established in the present study is comparable with the $81 \%$ induction response rate demonstrated in the initial infliximab induction trial by Targan et al (1), the $65 \%$ induction response rate demonstrated in ACCENT I (4) and the $88 \%$ induction response in the more recent pediatric A Randomized, Multicenter, Open-Label Study to Evaluate the Safety and Efficacy of Anti-TNF alpha Chimeric Monoclonal Antibody in Pediatric Subjects with Moderate to Severe Crohn's Disease (REACH) (20).

Relative to maintenance therapy, for patients who responded to infliximab induction and continued with regularly scheduled maintenance treatment, the proportion of patients with an ongoing infliximab-induced clinical response at 54 weeks was $64 \%$ in our cohort, similar to the $43 \%$ response in ACCENT I (4) and the 64\% response rate demonstrated in REACH (20). Importantly, the current study examined scheduled maintenance therapy beyond the oneyear time frame of the clinical trials and demonstrated that maintenance response to infliximab persists, but steadily falls (Figure 1) in the second year of maintenance therapy.

Despite the efficacy of infliximab maintenance therapy described in the current patient population, the results may have been underestimated given the fact that a significant number of patients in full response stopped infliximab maintenance for nonmedical (ie, insurance-related) reasons. In fact, of the 61 patients deemed to have 'lost response' to infliximab, 18 patients $(29.5 \%)$ did not experience either loss of clinical efficacy or adverse events. Instead, the 'loss of response' was due to the termination of third-party payments for the infliximab costs. If these patients were able to continue with maintenance treatments, the durability of the clinical response to infliximab might have been even more robust, although the outcomes are, necessarily, unknown.

A constraint of all nonclinical trials is the absence of response and remission in terms of a CDAI. This limits the direct comparison with the remission and response rates calculated in randomized clinical trials. Nevertheless, the physician global assessment of clinically relevant improvement in diarrhea, abdominal pain, extraintestinal symptoms and general wellbeing has been demonstrated to closely correlate with the

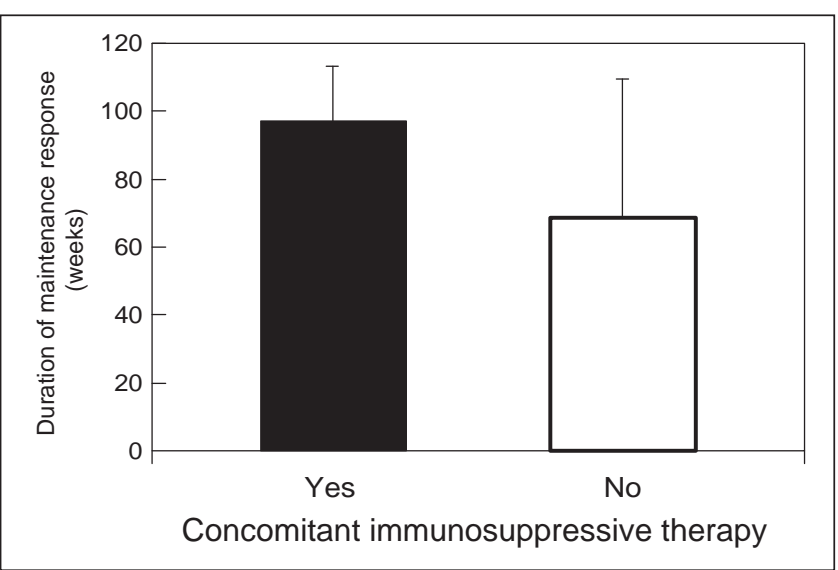

Figure 3) Duration of clinical response to maintenance infliximab relative to immunosuppressive therapy. Maintenance clinical response to infliximab was defined according to the physician's global assessment and the participant being off corticosteroids for patients using concomitant immunosuppressive therapy (solid bar) and for those not using concomitant immunosuppressive therapy (open bar)

calculated CDAI (see Methods section) (17). This global assessment was formally documented in each of the patient's files.

Two recent studies have also described single-centre longterm outcomes with maintenance infliximab therapy for Crohn's disease in a clinical practice setting, both of which used similar definitions of clinical response to those used in our study. The first (21), performed in a gastroenterology private practice in Minnesota, USA, followed the outcomes of 198 Crohn's disease patients and then used Kaplan-Meier survival estimates to predict the long-term durability of maintenance infliximab. Eighty-eight per cent of patients initially responded to infliximab and $66 \%$ maintained this response to 72 months with regular therapy every eight weeks. This would seem to exceed the long-term response of maintenance infliximab therapy demonstrated in our cohort. However, the Minnesota study did not consider the initiation or reinitiation of corticosteroids to constitute treatment failure, whereas we defined such corticosteroid use to be a loss of response, even if our patients were subsequently maintained on infliximab thereafter. Furthermore, patients in the Minnesota study were able to receive infliximab dose escalation or shortened dose intervals to counter waning clinical response without being classified as loss of response, whereas we defined this as loss of response in our patients.

The second study (22) described the long-term outcomes of infliximab treatment in 614 Crohn's disease patients in Leuven, Belgium. Different from our cohort, the patients included in this study had both luminal and fistulizing Crohn's disease, and were patients who received episodic and regularly scheduled maintenance infliximab. Again, different from our cohort, the Belgian group defined clinical response as "lasting control of the disease activity during follow-up with persistent improvement of the symptoms." In the Belgian cohort, $89 \%$ of patients responded to infliximab induction and of these responders, 63\% experienced ongoing clinical benefit with maintenance therapy after a median follow-up of 55 months. This study again demonstrated the maintenance infliximab response achievable in 'real-life' clinical practice, but outperformed the results achieved in our study because of less stringent definitions of loss of response. 
An important and clinically relevant question is the consideration of concomitant immunosuppressive therapy and its impact on the efficacy of maintenance infliximab treatment. In our cohort, $89 \%$ of patients were taking concomitant azathioprine, 6-MP or methotrexate during induction and with maintenance infliximab. Within our cohort, the proportion of patients with an ongoing clinical response and the overall duration of response was higher in the group using concomitant immunosuppression, although these data did not reach statistical significance. Recently, superior long-term maintenance of remission results have been demonstrated in studies using early concomitant azathioprine $(20,23)$, but not methotrexate (24) therapy. Furthermore, in the Minnesota study (21), 21 patients on an immunosuppressant for longer than three months before starting infliximab, had a longer duration of maintenance response, although this result did not reach statistical significance $(\mathrm{P}=0.088)$. Similarly, in the Belgian study (22), concomitant immunosupression therapy at the initiation of infliximab numerically, but not statistically, influenced long-term clinical response, yet statistically reduced immunogenicity.

\section{SUMMARY}

The patients treated with infliximab therapy for luminal Crohn's disease in our inflammatory bowel disease outpatient subspecialty clinic achieved excellent induction and maintenance of response, confirming the real-life effectiveness of maintenance infliximab established in clinical trials.

\section{REFERENCES}

1. Targan SR, Hanauer SB, van Deventer SJ, et al. A short-term study of chimeric monoclonal antibody cA2 to tumor necrosis factor alpha for Crohn's disease. Crohn's Disease cA2 Study Group. N Engl J Med 1997;337:1029-35.

2. Present DH, Rutgeerts P, Targan S, et al. Infliximab for the treatment of fistulas in patients with crohn's disease. N Engl J Med 1999;340:1398-405.

3. D'Haens G, Baert F, van Assche G, et al. Early combined immunosuppression or conventional management in patients with newly diagnosed Crohn's disease: An open randomised trial. Lancet 2008;371:660-7.

4. Hanauer SB, Feagan BG, Lichtenstein GR, et al. Maintenance infliximab for Crohn's disease: The ACCENT I randomised trial. Lancet 2002;359:1541-9.

5. Sands BE, Anderson FH, Bernstein CN, et al. Infliximab maintenance therapy for fistulizing Crohn's disease. N Engl J Med 2004:350:876-85.

6. Cohen RD, Tsang JF, Hanauer SB. Infliximab in Crohn's disease: First anniversary experience. Am J Gastroenterol 2000;95:3469-77.

7. Ricart E, Panaccione R, Loftus EV, et al. Infliximab for Crohn's disease in clinical practice at the Mayo Clinic: The first 100 patients. Am J Gastroenterol 2001;96:722-9.

8. Hommes DW, van de Heisteeg BH, van der Spek M, et al. Infliximab treatment for Crohn's disease: One-year experience in a Dutch academic hospital. Inflamm Bowel Dis 2002;8:81-6.

9. Vermeire S, Louis E, Carbonez A, et al. Demographic and clinical parameters influencing the short-term outcome of anti-tumor necrosis factor (infliximab) treatment in Crohn's disease. Am J Gastroenterol 2002;97:2357-63.

10. Wenzl HH, Reinisch W, Jahnel J, et al. Austrian infliximab experience in Crohn's disease: A nationwide cooperative study with long-term follow-up. Eur J Gastroenterol Hepatol 2004;16:767-73.

11. Rutgeerts P, Feagan BG, Lichtenstein GR, et al. Comparison of scheduled and episodic treatment strategies of infliximab in Crohn's disease. Gastroenterology 2004;126:402-13.

12. Rutgeerts P, Diamond RH, Bala M, et al. Scheduled maintenance treatment with infliximab is superior to episodic treatment for the healing of mucosal ulceration associated with Crohn's disease. Gastrointest Endosc 2006;63:433-42.
ACKNOWLEDGEMENT: The authors thank Dr Eoin Lalor (University of Alberta, Edmonton, Alberta) for contributing patients to this study.

STATEMENT OF INTERESTS: Dr Richard Fedorak is an advisory board member for: Abbott Canada, Axcan, Celltech, Elan/ Biogen, Proctor \& Gamble, Schering Canada, Shire, UCB Pharma, VSL\#3, Genentech; a participant in the speaker's bureau for: Abbott, Altana/Nycomed, Axcan, Ferring, Proctor \& Gamble, Schering, Shire, UCB Pharma, VSL\#3; a recipient of consultation fees for Abbott, Altana/Nycomed, Axcan, Berlex, Bristol Myers Squibb, Centocor, Ferring, Novartis, Otsuka, Proctor \& Gamble, Protein Design Labs, Schering, Synta, UCB Pharma and VSL\#3 Genentech; a recipient of clinical/basic research grants from Abbott, Altana/Nycomed, Axcan, Berlex, Bristol Myers Squibb, Centocor, Elan/Biogen, Ferring, Millenium, Novartis, Otsuka, Proctor \& Gamble, Protein Design Labs, Schering, UCB Pharma and VSL\#3. Dr Levinus Dieleman receives consultation fees from Schering-Plough and Abbott, and has received research grants from Oraft. Dr Christopher Teshima has received a Canadian Institutes of Health Research (CIHR)/Canadian Association of Gastroenterology (CAG) research fellowship award sponsored by Ferring Canada. Adrienne Thompson and LeRose Dhanoa have no personal interests to declare.

DECLARATION OF STUDY FUNDING INTERESTS: None to declare.

13. Colombel JF, Loftus EV Jr, Tremaine WJ, et al. The safety profile of infliximab in patients with Crohn's disease: The Mayo Clinic experience in 500 patients. Gastroenterology 2004;126:19-31.

14. Ljung T, Karlen P, Schmidt D, et al. Infliximab in inflammatory bowel disease: Clinical outcome in a population based cohort from Stockholm county. Gut 2004;53:849-53.

15. Lichtenstein GR, Feagan BG, Cohen RD, et al. Serious infections and mortality in association with therapies for Crohn's disease: TREAT registry. Clin Gastroenterol Hepatol 2006;4:621-30.

16. Panaccione R, Fedorak RN, Aumais G, et al. Canadian association of gastroenterology clinical practice guidelines: The use of infliximab in Crohn's disease. Can J Gastroenterol 2004;18:503-8.

17. Best WR, Becktel JM, Singleton JW, et al. Development of a Crohn's disease activity index. National Cooperative Crohn's Disease Study. Gastroenterology 1976;70:439-44.

18. Sandler RS, Jordan MC, Kupper LL. Development of a Crohn's index for survey research. J Clin Epidemiol 1988;41:451-8.

19. Fedorak RN, Bitton A, Hassard P, et al. Infliximab dose in real-life remains stable over 30 months with favourable benefit: Risk profile in CD. Gastroenterology 2007;132(S2):A180.

20. Hyams J, Crandall W, Kugathasan S, et al. Induction and maintenance infliximab therapy for the treatment of moderate-tosevere Crohn's disease in children. Gastroenterology 2007;132:863-73.

21. Rudolph SJ, Weinberg DI, McCabe RP. Long-term durability of Crohn's disease treatment with infliximab. Dig Dis Sci 2008;53:1033-41.

22. Schnitzler F, Fidder H, Ferrante M, et al. Long-term outcome of treatment with infliximab in 614 Crohn's disease patients: Results from a single centre cohort. Gut 2009;58:492-500.

23. Sandborn W, Rugeerts P, Reinisch W, et al. SONIC: A randomized, double-blind, controlled trial comparing infliximab and infliximab plus azathioprine to azathioprine in patients with Crohn's disease naive to immunosuppressives and biologic therapy [late breaking abstract]. Am J Gastroenterol 2008;103(S1):1117.

24. Feagan BG, McDonald J, Ponich T, et al. A randomized trial of methotrexate (MTX) in combination with infliximab (IFX) for the treatment of Crohn's disease (CD) [late-breaking abstract]. Gastroenterology 2008;134(S1):682c. 


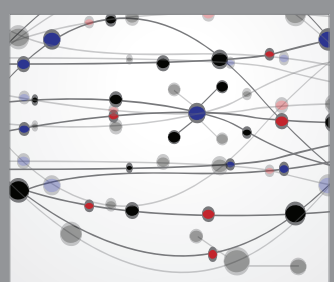

The Scientific World Journal
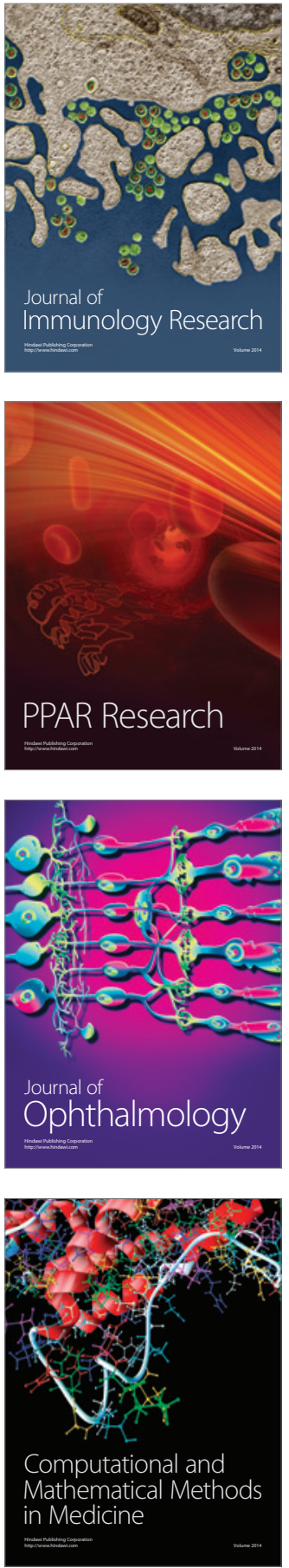

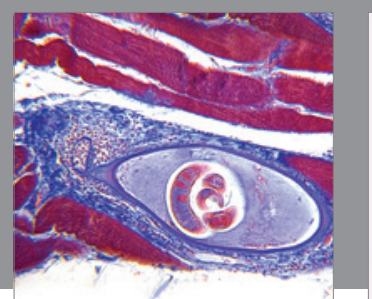

Gastroenterology Research and Practice

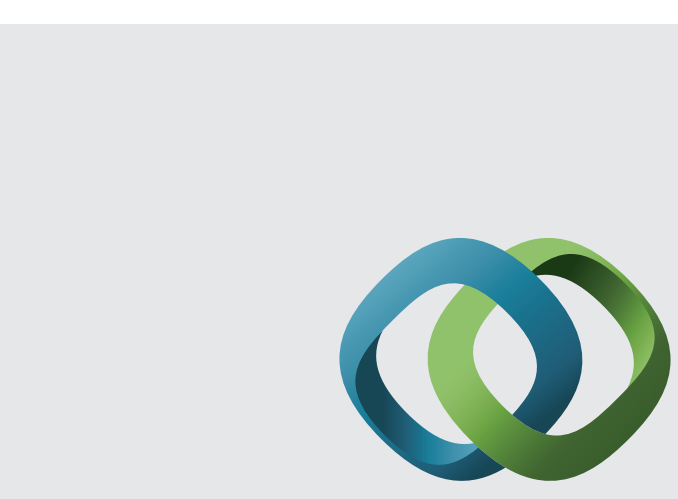

\section{Hindawi}

Submit your manuscripts at

http://www.hindawi.com
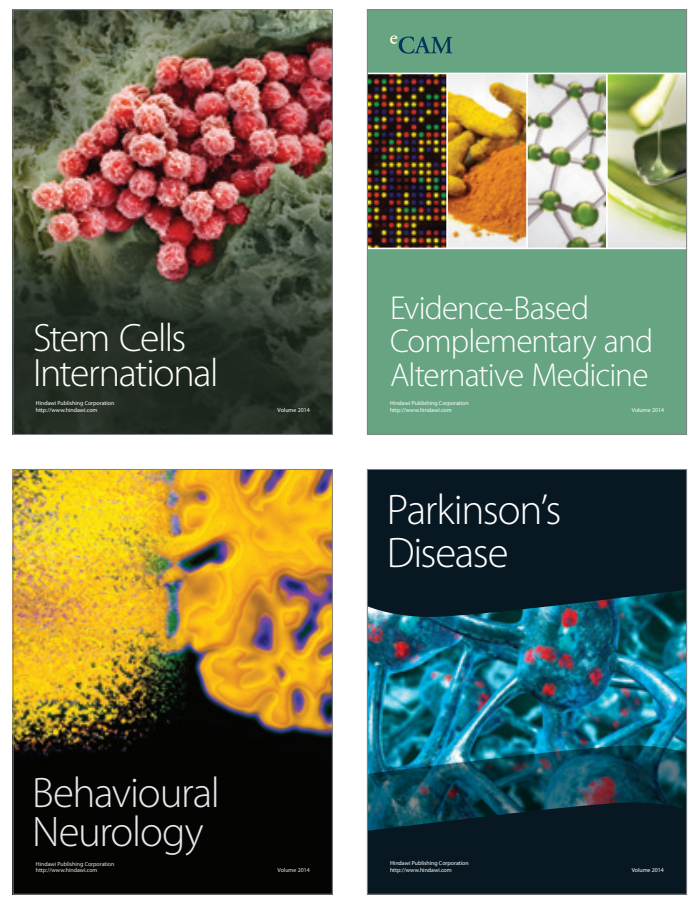
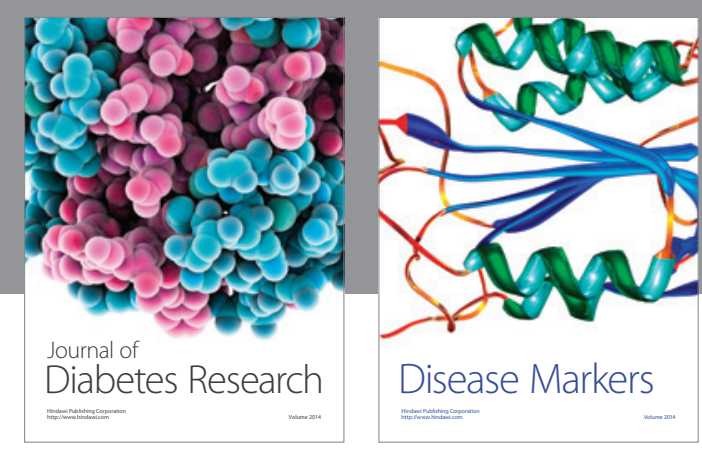

Disease Markers
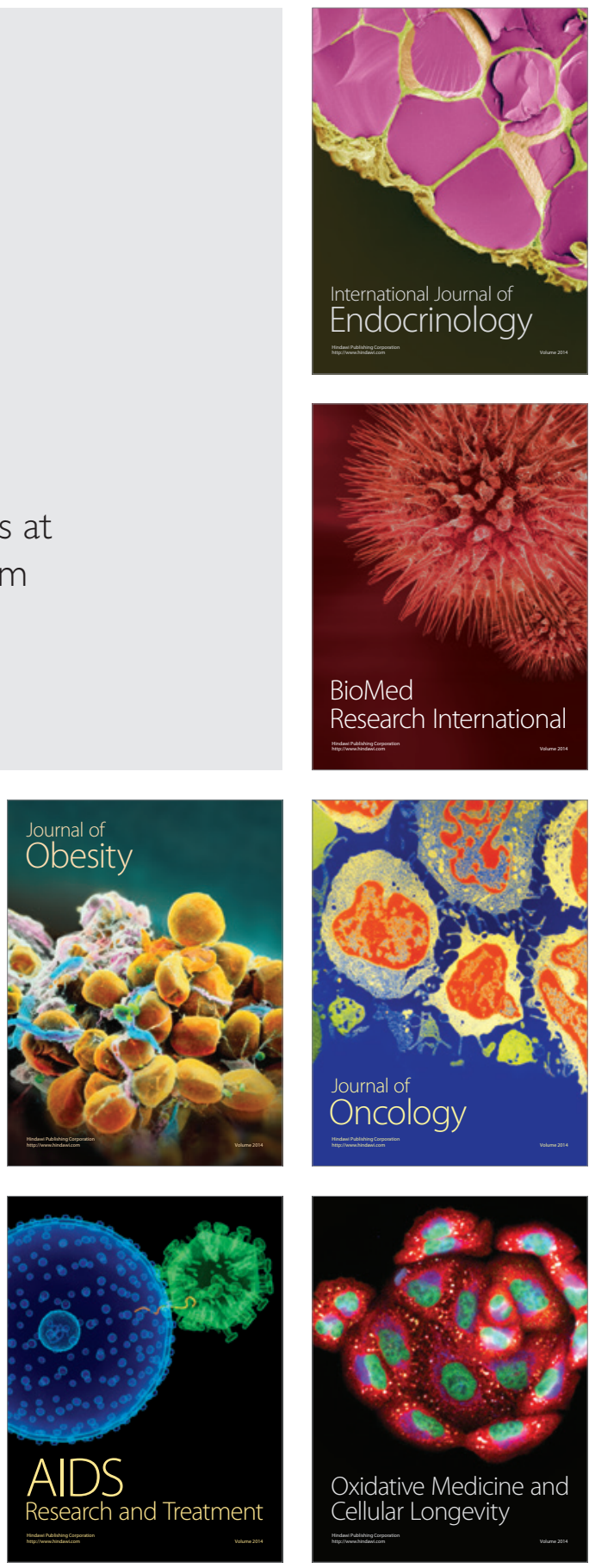